\title{
Persantunan
}

Kami berterima kasih kepada para mitra bestari yang telah berkenan meluangkan waktu serta mencurahkan

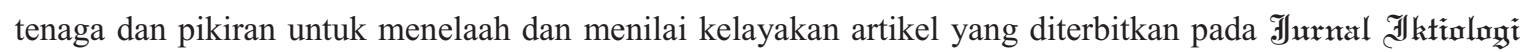
IInnomestat Volume 19 Nomor 1 Bulan Februari Tahun 2019, yaitu:

Ali Suman, Prof. Dr. (Pusat Riset Perikanan, Badan Riset dan Sumber daya Manusia Kelautan dan Perikanan

Brata Pantjara, Prof. Dr. (Balai Riset Perikanan Budidaya Air Tawar dan Penyuluhan Perikanan, Bogor)

Didik Wahyu Hendro Tjahjo Dr. (Balai Riset Pemulihan Sumber Daya Ikan, Jatiluhur)

Djamhuriah S. Said, MSi (Pusat Penelitian Limnologi - Lembaga Ilmu Pengetahuan Indonesia, Cibinong)

Eddy Supriyono Dr. (Departemen Budidaya Perairan, Fakultas Perikanan dan Ilmu Kelautan, Institut Pertanian Bogor)

Emmanuel Manangkalangi Dr. (Fakuktas Perikanan dan Ilmu Kelautan UNIPA - Manokwari)

Fahmi Dr. (Pusat Penelitian Oseanografi - Pusat Penelitian Oseanografi-LIPI)

Gunawan Pratama Yoga Dr. (Pusat Penelitian Limnologi - Lembaga Ilmu Pengetahuan Indonesia, Cibinong)

Iis Diatin, Dr. (Departemen Budidaya Perairan, Fakultas Perikanan dan Ilmu Kelautan, Institut Pertanian Bogor)

Imron Dr. (Balai Penelitian Pemuliaan Ikan, Sukamandi)

Irmawati Dr. (Fakultas Ilmu Kelautan dan Perikanan, Universitas Hasanuddin

Laksmi Sulmartiwi Dr. (Fakultas Perikanan dan Kelautan, Universitas Airlangga)

Melta Rini Fahmi Dr. (Balai Penelitian dan Pengembangan Budidaya Ikan Hias, Depok)

Mulyono S Baskoro Prof. Dr. (Departemen Pemanfaatan Sumberdaya Perikanan, FPIK - IPB)

Nina Meilisza Dr. (Balai Penelitian dan Pengembangan Budidaya Ikan Hias, Depok) 


\section{PANDUAN bagi PENULIS}

Jurnal Iktiologi Indonesia (JII) menyajikan artikel yang berkenaan dengan segala aspek kehidupan ikan (Pisces) di perairan tawar, payau, dan laut. Aspek yang dicakup antara lain biologi, fisiologi, taksonomi dan sistematika, genetika, dan ekologi, serta terapannya dalam bidang penangkapan, akuakultur, pengelolaan perikanan, dan konservasi. Artikel yang dimuat merupakan hasil lengkap suatu penelitian.

JII mengundang kepada siapapun untuk menulis resensi buku yang berkaitan dengan aspek-aspek tersebut di atas dan mempublikasikan. Ulas balik (review) suatu topik yang dipandang penting dan aktual ditulis seorang pakar atas permintaan dewan penyunting. Komentar dan atau tanggapan atas suatu artikel yang dimuat disediakan ruang.

JII diterbitkan tiga kali setahun (Februari, Juni, dan Oktober). Pada nomor terakhir tiap volume dimuat daftar isi, indeks penulis, dan indeks subyek.

Artikel dapat ditulis dalam Bahasa Indonesia atau Bahasa Inggris. Artikel belum pernah diterbitkan pada media manapun. Dewan Penyunting akan menerima atau menolak artikel berdasarkan kesesuaian materi dengan ruang lingkup JII, dan meringkas atau menyunting artikel bila diperlukan untuk menyesuaikan dengan halaman yang tersedia tanpa mengaburkan substansi. Opini yang tertuang dalam tulisan artikel tidak menggambarkan kebijakan penyunting.

Untuk semua keperluan, penulis pertama dianggap sebagai penulis korespondensi artikel, kecuali ada keterangan lain. Penulis, yang artikelnya disetujui untuk diterbitkan, bersedia mengalihkan hak cipta naskah kepada penerbit (Masyarakat Iktiologi Indonesia). Cetakan awal akan dikirimkan kepada penulis korespondensi untuk mendapatkan tanggapan. Tanggapan penulis dan surat persetujuan pengalihan hak cipta segera dikirim ke penyunting dalam waktu satu minggu.

Dalam hal penemuan baru, disarankan kepada penulis untuk mengurus hak patennya sebelum mempublikasikan dalam jurnal ini.

\section{Pengajuan naskah}

Pengajuan naskah dapat dilakukan kapan pun dengan mengirimkan satu salinan lunak (soft copy) kepada dewan penyunting JII melalui laman:

$$
\text { jurnal-iktiologi.org }
$$

dan melalui surat elektronik dengan alamat: iktiologi_indonesia@yahoo.co.id

Naskah yang diterima penyunting akan ditelaah oleh dua mitra bestari anonim yang kompeten untuk memperoleh penilaian konstruktif agar mendapatkan suatu taraf publikasi yang tinggi.

Panduan berikut membantu anda dalam penyiapan naskah yang akan dikirimkan ke JII. Naskah yang ditulis sesuai dengan ketentuan pada panduan akan mempercepat waktu pemeriksaan dan penyuntingan.

\section{Penyiapan naskah}

Pastikan bahwa naskah cukup jelas untuk disunting, dengan mengikuti hal berikut:

- Ukuran kertas: A4 dengan batas pinggir $3 \mathrm{~cm}$ seluruhnya, bernomor halaman yang dituliskan pada ujung kanan bawah.

- Naskah ditulis dalam satu kolom pada tiap halaman.

- Naskah diketik menggunakan Microsoft Word for Windows dalam spasi 1,5 baris, tipe huruf Times New Roman ukuran 12. Karakter huruf pada Gambar dapat berbeda dari ketentuan ini.

- Teks dituliskan hanya rata kiri.

- Gunakan spasi tunggal (bukan ganda) sesudah tanda baca (titik, koma, titik dua, titik koma).

- Gunakan satuan Sistem Internasional (SI) untuk pengukuran dan penimbangan.

- Nama ilmiah organisme disesuaikan dengan kode nomenklatur internasional (e.g. International Code of Zoological Nomenclature). Nama genus dan spesies ditulis dalam huruf mi-ring (italik).

- Tidak menggunakan garis miring (sebagai ganti kata per), tetapi menggunakan tika atas indeks minus, contoh $9 \mathrm{~m} /$ det dituliskan $9 \mathrm{~m}$ $\operatorname{det}^{-1}$.

- Jangan menggunakan singkatan tanpa keterangan sebelumnya. Kata yang disingkat sebaiknya ditulis lengkap pada penyebutan pertama diikuti singkatan dalam tanda kurung

- Tanggal ditulis sebagai 'hari bulan tahun', misal 12 September 2010. Singkatan bulan pada tabel dan gambar menggunakan tiga kata pertama nama bulan, misal Feb, Jun, Okt. 
- Peta memuat petunjuk garis lintang dan garis bujur, serta menyebutkan sumber data.

- Gambar atau foto organisme atau bagian organisme harus diberi keterangan skala.

- Periksa untuk memastikan bahwa gambar telah diberi nomor secara benar seperti yang dikutip dalam teks. Nomor dan judul gambar terletak di bagian bawah gambar.

- Pastikan bahwa tabel telah diberi nomor dengan benar dan berurutan sesuai dengan nomor yang dikutip dalam teks. Posisi nomor dan judul tabel terletak di atas tabel. Judul seba-iknya jelas, lengkap dan informatif. Letakkan sumber data dan catatan tepat di bawah tabel. Jangan memuat garis vertikal pada tabel. Hilangkan garis horisontal dari tabel, kecuali garis atas dan bawah judul kolom dan garis akhir dasar tabel.

- Ketepatan pengutipan pustaka sepenuhnya menjadi tanggung jawab penulis. JII menganut sistem nama-tahun dalam pengutipan. Nama keluarga dan tahun publikasi dicantumkan dalam teks eg. Rahardjo \& Simanjuntak (2007) atau (Rahardjo \& Simanjuntak 2007) untuk satu dan dua penulis; Sjafei et al. (2008) atau (Sjafei et al. 2008) untuk penulis lebih dari dua. Penulisan banyak pustaka kutipan dalam teks diurutkan dari yang tertua eg. (Gonzales et al. 2000, Stergiou \& Moutopoulos 2001, Khaironizam \& NormaRashid 2002, Abdurahiman et al. 2004, Frota et al. 2004; dan Tarkan et al. 2006). Pustaka bertahun sama disusun berurut menurut abjad penulis. Pustaka dari penulis yang sama dan dipublikasikan pada tahun yang sama dibedakan oleh huruf kecil (a, b, c dan seterusnya) yang ditambahkan pada tahun publikasi, eg. Syafei 2018a, Syafei 2018b.

\section{Bagian-bagian naskah}

Judul ditulis di tengah dengan huruf tebal berukuran 13 dan terjemahan ditulis dengan huruf biasa berukuran 11. Judul hendaknya singkat, tepat, dan informatif yang mencerminkan isi artikel.

Nama penulis ditulis dengan huruf biasa berukuran 12. Alamat ditulis dengan huruf biasa berukuran 9, yang memuat nama dan alamat lembaga disertai kode pos. Cantumkan alamat surat elektronik semua penulis.
Abstrak ditulis dalam Bahasa Indonesia dan Inggris tidak melebihi 250 kata. Abstrak memuat tujuan, apa yang dilakukan (metode), apa yang ditemukan (hasil), dan simpulan. Hindari singkatan dan kutipan pustaka. Abstrak terdiri atas satu alinea.

Kata penting ditulis dalam Bahasa Indonesia dan Inggris tidak melebihi tujuh kata yang disusun menurut abjad.

Pendahuluan menjelaskan secara utuh dan jelas alasan mengapa studi dilakukan. Hasil-hasil sebelumnya yang terkait dengan studi anda (state of the art) dirangkum dalam suatu acuan yang padat. Nyatakan tujuan penelitian anda.

Bahan dan metode dituliskan secara jelas. Teknik statistik diuraikan secara lengkap (jika baru) atau diacu.

Hasil. Di sini anda kemukakan informasi dan hasil yang diperoleh berdasarkan metode yang digunakan. Jangan mengutip pustaka apapun pada bab ini.

Pembahasan. Nilai suatu naskah ditentukan oleh suatu pembahasan yang baik. Di sini hasil studi anda dihubungkan dengan hasil studi sebelumnya. Hasil diinterpretasikan dengan dukungan kejadian atau pustaka yang memadai. Hasil yang tidak diharapkan atau anomali perlu dijelaskan. Penggunaan pustaka primer mutakhir (10 tahun terakhir) sangat dianjurkan.

Simpulan dinyatakan secara jelas dan ringkas, serta menjawab tujuan penelitian.

Persantunan (bila perlu) memuat lembaga atau orang yang mendukung secara langsung penelitian atau penulisan naskah anda.

Daftar pustaka disusun menurut abjad nama penulis pertama. Pastikan semua pustaka yang dikutip dalam teks tertera di daftar pustaka, dan demikian pula sebaliknya.

- Judul terbitan berkala dikutip lengkap (ditulis dalam huruf italik), yang diikuti oleh volume dan nomor terbitan, serta nomor halaman dalam huruf roman (tegak). Contoh:

Lauer TE, Doll JC, Allen PJ, Breidert B, Palla J. 2008. Changes in yellow perch length frequencies and sex ratios following closure of the commercial fishery and reduction in sport bag limits 
in southern Lake Michigan. Fisheries Management and Ecology, 15(1): 39-47

- Judul buku ditulis dalam huruf italik. Gunakan huruf kapital pada awal kata, kecuali kata depan dan kata sambung. Nama dan lokasi penerbit, serta total halaman dicantumkan. Contoh:

Berra TB. 2001. Freshwater Fish

Distribution. Academic Press, San Francisco. 640 p.

- Buku terjemahan ditambahkan nama penerjemahnya. Contoh:

Nikolsky GV. 1963. The ecology of fishes. Translated from Russian by L. Birkett. Academic Press, London and New York. 352 p.

Steel GD, Torrie JH. 1981. Prinsipprinsip dan Prosedur Statistika. Diterjemahkan oleh Bambang Sumantri. PT. Gramedia Pustaka Utama. Jakarta. 747 p.

- Artikel yang termuat dalam kumpulan monograf (buku, prosiding) dituliskan: penulistahun, judul artikel. In: nama penyunting, judul monograf (ditulis dengan huruf italik), nama penerbit dan lokasinya, serta halaman artikel. Contoh:

Bleckmann H. 1993. Role of lateral line in fish behaviour. In: Pitcher TJ (ed.). Behaviour of Teleost Fishes. Chapman and Hall, London. pp. 201-246.

Simanjuntak CPH, Zahid A, Rahardjo MF, Hadiaty RK, Krismono, Haryono, Tjakrawidjaja AT (Editor). 2011. Prosiding Seminar Nasional Ikan VI. Bogor 8-9 Juni 2010. Masyarakat Iktiologi Indonesia. Cibinong. $612 \mathrm{p}$.

- Kutipan terbatas hasil yang tak dipublikasikan, pekerjaan yang dalam penyiapan, pekerjaan yang baru diusulkan, atau komunikasi pribadi hanya dibuat dalam teks, di luar Daftar Pustaka.

- Artikel dan buku yang belum dipublikasikan dan sedang dalam proses pencetakan diberi tambahan "in press". Contoh:

Rahardjo MF, Syafei LS. 2020. Spesies Invasif Akuatik. (in press)

Artikel ulas balik suatu topik, resensi buku, dan komentar atau tanggapan atas suatu artikel tidak perlu mengikuti sistematika penulisan di atas. 


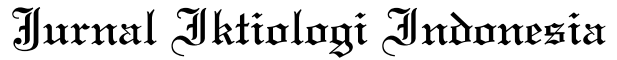

Volume 20 Nomor 1 Februari 2020

Dara Sarasita, Agung Yunanto, Defri Yona Kandungan mikroplastik pada empat jenis ikan ekonomis penting di perairan Selat Bali [Microplastics abundance in four different species of commercial

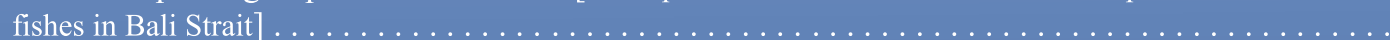

Alfis Syahril, Odang Carman, Dinar Tri Soelistyowati Tetraploidisasi kejut suhu dingin pada ikan patin siam Pangasianodon hypophthalmus (Sauvage, 1878) dengan suhu dan umur zigot yang berbeda [Cold temperature shock tetraploidization of striped catfish Pangasianodon hypophthalmus (Sauvage, 1878) with different of temperature and age of zygote $] \ldots \ldots \ldots \ldots \ldots \ldots \ldots \ldots \ldots$

Selvia Oktaviyani, Wanwan Kurniawan, Fahmi Komposisi spesies dan distribusi ukuran hiu dan pari yang tertangkap di Selat Bali dan perairan sekitarnya serta kaitannya dengan pengelolaan perikanan) [Species composition and size distribution of sharks and rays caught in Bali Strait and its surrounding area and its relation to fisheries management) $] \ldots \ldots \ldots \ldots \ldots \ldots \ldots \ldots \ldots \ldots$

Ahmad Teduh, Dinar Tri Soelistyowati, Odang Carman, Harton Arfah Produksi albino slayer melalui kombinasi persilangan pada ikan hias brushmouth (Hypostomus plecostomus, Linnaeus 1758) [Production of albino slayer through a combination of crossing in brushmouth (Hypostomus plecostomus, Linnaeus 1758) ornamental fish $] \ldots \ldots \ldots \ldots \ldots \ldots \ldots \ldots \ldots \ldots \ldots \ldots \ldots \ldots \ldots \ldots \ldots \ldots \ldots \ldots$

Rina Hirnawati, Dedi Jusadi, Julie Ekasari, Muhammad Agus Suprayudi Evaluasi kualitas warna dan aktivitas antioksidan yuwana ikan botia Chromobotia macracanthus Bleeker 1852 dengan penambahan astaksantin dalam pakan [Color quality and antioxidant activity evaluation of clown loach juvenile, Chromobotia macracanthus Bleeker 1852 by addition of astaxanthin in diet] .

Kunto Wibowo, Miftahul Huda, Rachmad Sholeh Wicaksono, Monica Bataona, Teguh Peristiwady Catatan distribusi ikan buntal laut dalam langka Triodon macropterus (Tetraodontiformes: Triodontidae) dari Laut Maluku dan Laut Sawu [Records of the rare deep-sea threetooth puffer fish, Triodon macropterus (Tetraodontiformes: Triodontidae) from Molucca and Sawu seas, Indonesia]. . . . . . . .

I Nyoman Y. Parawangsa, M. Fadjar Rahardjo, Charles P. H. Simanjuntak Aspek reproduksi ikan ekor pedang, Xiphophorus hellerii Heckel 1848 di Danau Tamblingan, Bali [Reproduction aspect of green swordtail, Xiphophorus hellerii Heckel 1848 in Tamblingan Lake, Bali] . . . . . . . . . . . .

Muh. Herjayanto, Mas Bayu Syamsunarno, Nugroho Agung Prasetyo, Annisa Misykah Mauliddina, et al. Studi awal pengangkutan sistem tertutup, pemeliharaan dan pengamatan telur Oryzias javanicus (Bleeker 1854) asal Pulau Tunda [Preliminary study of closed system transportation, rearing and observation of the eggs Oryzias javanicus (Bleeker 1854) from Tunda Island] . . . . . . . . . . 